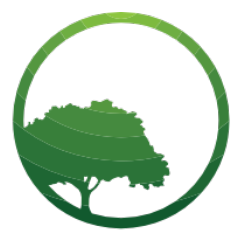

Business \& Social Science IJRBS

\section{Research in Business and Social Science}

IJRBS Vol 8 No 3, Special Issue ISSN: 2147-4478

Contents available at www.ssbfnet.com/ojs

\title{
An Empirical Analysis of the Pageview and Visit Duration of Pornography Websites
}

\section{Chatpong Tangmanee}

\author{
Corresponding Author: Chulalongkorn Business School, Chulalongkorn University, Bangkok \\ 10330, Thailand.
}

ORCID ID: 0000-0001-6805-2921

\begin{abstract}
A positive relationship between pageview and visit duration has been identified for several types of websites, including retail. However, pornography websites offer such explicitly sexual content that viewers might stay on one page so long that it could distort the positivity. Yet, no empirical work has investigated this matter and little has focused on visit behavior to adult websites. Based on 473,840 visit sessions to pornography websites targeting both (1) the public and (2) the homosexual viewers, the 0.771 correlation coefficient between the pageview and the visit duration is statistically significant. It confirms that these two variables are positively related in the online pornography context. We also found that the viewer's sexual orientation may have a moderating effect on the relationship between them. In addition to extending the theoretical insights into online visit behavior to pornography websites, online practitioners may apply the findings in order to retain visitors to their websites.
\end{abstract}

Key words: Empirical Analysis, Pageview, Visit Duration, Pornography Websites

JEL classification: C83, M15

Submitted: 24.03.2019 - Accepted: 28.04.2019

\section{Introduction}

Electronic commerce has grown exponentially. The total amount of online sales is predicted to reach US\$ 4.06 trillion in 2020 (Chaffey, 2017). Not only has the number of online transactions been increasing, but the amount of traffic on the Internet has also been consistently heavy (Statista, 2017). Almost $50 \%$ of online traffic in the US in 2017 was direct - that is, visitors know which websites they want to visit (Desjardins, 2017). Despite this growth, only 3\% of the visits to retail websites in 2016 ended with a purchase (Pallant, Danaher, Sand, \& Danaher, 2017). This may imply an individual visits a website for non-transactional purposes. For instance, it is common that customers research products online prior to making the final decision to purchase them offline (Danaher, Mullarkey, \& Essegaier, 2006). Also, checking product reviews on websites is a widely accepted practice. A few typology sets covering online visits have been proposed and tested (Moo, 2003; Pallant, et al., 2017). Using a cluster modeling technique, Pallant, et al. (2017) classified online visit behavior into five major clusters, four of which confirmed what Moo (2013) had 
discovered. However, the fifth was unique - the "cart-only" label. This group uses the cart as a tool to arrange their shopping (Pallant, et al., 2017). Yet, there still exists visitors who browse websites but make no purchase. Furthermore, most visits to social media or content-sharing websites are non-transactional. In 2014, the proportion of visits to Facebook was about $10 \%$ higher than in the previous year (Price, 2018). Also, $60 \%$ or higher of Facebook accounts in the US shared content a few times a week (D'Ottavio, 2018).

In addition, a sizeable number of empirical studies have ascertained specific figures regarding online visit behavior, including the number of webpages visited (hereafter referred to as pageview), the visit duration, or the basket value. For instance, Tangmanee (2017) confirmed the significant difference of the pageviews and that of the visit duration between experience and search goods. His findings replicated what other researchers had discovered (Lin, et al., 2010; Xun, 2015). Given these empirical findings, it is reasonable to claim the positive correlation between pageview and visit duration. In other words, the correlation between these two visit behaviors is validated in the context of retail websites. However, there are non-transactional websites offering no product for purchase. The websites nonetheless still have high business value arising from the enormous amount of traffic. Examples of social media websites include Facebook or content-sharing websites like YouTube. Since visits to non-transactional websites, especially content-sharing ones, do not necessarily end with a purchase, the correlation between pageview and duration might differ from that in the online retail context and this has largely been left unexplored.

Among the content-sharing websites, we are particularly interested in those sharing sexual explicitly content. These websites are commonly known as pornography websites. Our interest stems from three motivations. First, the adult business is a lucrative industry. Its long history started in the printed and film business before evolving into the digital format now accessible on the Internet (Johnson, 2011; McNeil, Osbone \& Pavia, 2005). In $2017,50 \%$ or higher of the Internet users in the US accepted they had paid US $\$ 25$ or more annually for the subscription to adult-related websites (Statista, 2018). Second, while online retailing has long received enormous research attention (Danaher, et al., 2006; Mallapragada, et al., 2016; Pallant, et al., 2017; Tangmanee, 2017), examination on non-retailing has been overlooked. Among the scant body of online nonretailing studies, a relatively large amount of focus has been on social media. One possible reason is that the business of sharing sexually explicitly sexual content has been neglected is because of its negative effects (McCormick \& Wignall, 2017). Pornography has been researched and blamed as a major cause of female degradation and domestic violence (Johnson, 2011). Despite the negativity, sexual issues and adult contents do have positive impact. Finally, the remarkable collection of empirical research appears to confirm the positive correlation between pageview and visit duration in retail websites (Mallapragada, et al., 2016; Tangmanee, 2017). Logically, the longer the stay in a website, the higher the pageview, or vice versa. However, such positivity may not exist in sexually explicit content sharing websites. A person visits a pornography collection in order to enjoy adult material. The content might be so interesting that the length of his or her stay on the particular page is very long. Such behavior could ultimately falsify the positive connection between the pageview and the visit duration. As a result, the current study attempts to report the pageview and the visit duration figures in the context of pornography websites and to analyze the correlation between these two constructs.

\section{Literature Review}

A pornography website in the current study is defined as a web-based address containing sexually explicit content which targets adults. In general, visitors may access a pornography website directly by typing its uniform resource locator (URL) or indirectly through a link embedded in other websites. Visitors may select to watch any content, after which they may choose to visit other pages or to end a session when they either leave the websites or close the browser tab (or window). Basically, pornography websites are nontransactional in that they attempt to sell no items. Rather, they hope for high online traffic (Chaffey, 2017). In 2010, out of one million active websites in the world, around 42,000 were adult websites (CovenantEyes, 2015). In fact, it is predicted that by $2019,80 \%$ of the world's Internet traffic will be about sex-related content (Marshall, 2015).

While much research has focused upon visit behavior on retail websites (Mallapragada, et al., 2016; Moe, 2003; Pallant, et al., 2017), non-transactional websites including pornographic ones, appear to receive 
relatively little attention. This overlooked area is greatly surprising given the large business associated with online pornography. The online commercial adult industry is worth about US\$ 97 billon (Keilty, 2018). Every year, about 600 adult movies are released in Hollywood, netting a profit of US\$10 billion (Strange But True, 2017). The profitability of the adult business was further evidenced by the breakthrough of Royalle (1993), one of the first female adult movie producers. Ropelato (2017) identified approximately 4.2 million adult websites as primarily targeting 28,000 male visitors worldwide.

Success in the adult business has become increasingly visible since pornography has extended to the online platform (Macmillen, 2017). Pornhub is one of the most successful adult websites targeting general viewers. In 2017, its financial value was US\$ 58.24 million with a daily average of 81 million visitors (Silver, 2018). Also, pornography websites satisfying specific groups of viewers (e.g., homosexuals) have been seen profits as well (Brenen, 2018; Mosley, 2018). Brenen (2018) stated that most adult websites offer no items for purchase; rather, they anticipate a high amount of traffic. Owners of these adult websites thus opt for substantially sophisticated algorithms in order to attract and retain large volumes of traffic. Visitor's browsing behavior is also stored and analyzed in order to personalize pornographic materials to fit each visitor (Keilty, 2018).

People have long been enjoying pornography materials. According to McCormick, et al. (2017), adult content has become well accepted since its printed version with the format evolving into video and now as an online platform accessible through desktop computers, tablets, or mobiles (Kimball, 2017; Keilty, 2018; Johnson, 2011). Given a statement from Pornhub Insights (2017), only 1\% of the traffic to Pornhub in 2008 was from mobile devices; in 2017 , it was $75 \%$. The popularity of adult content is so widespread that viewing can become additive (Kimball, 2017). Search services on the Internet have assisted users in accessing adult materials. In 2009, "porn" was frequently used as a keyword on YouTube (CovenantEyes, 2015). Given the increasing number of specific target groups of online pornography, the use of the search phrase, "Porn for women" has also grown significantly during 2016-2017 (Mosley, 2018; Castleman, 2016). Alexa research examined the world's top ten search engines and discovered that "sex" was one of the most popular search terms (CovenantEyes, 2015). Moreover, sex, pornography and adult matters rank second in what Internet users search for online (Lai, et al., 2017). A social network analysis of the online commercial adult industry in 2011 confirmed its high profitability (Johnson, 2011). In sum, all the figures and findings above provide solid evidence of the enormous and successful volume of the online adult industry.

Nonetheless, academic researchers have paid little attention to online pornography largely arising from its "negative" effect (CovenantEyes, 2015). Opposition to porn often claims that adult content: (1) promotes female objectification, and (2) conveys violent images to the detriment of culture and the society. On the other hand, those in support argue that the content is highly useful psychologically plus gender objectification is rarely evident (Davin, 2017; Role, 2017). Moreover, Mosley (2018) claims that the online platform allows women to access pornographic content in a secure environment. Also, the visit to an adult website is much more comfortable if it is anonymous (Dhyana, 2018). Such easy access may be one major drive behind the success of online adult content.

Online business is constantly interested in how website visitors behave during their visits stemming from the substantial amount of empirical research confirming the positive relationship between behavior and basket value. Moe (2003) classified the purpose of the retail website visit into four categories based on visitors' purchase horizon and their search behavior. While the direct-buying category heavily relates to basket value, the other three (i.e., hedonic browsing, knowledge building, and search/deliberation categories) slightly relate to online purchasing. Recently, Pallant, et al. (2017) revisited Moe's (2003) typology and classified online visit behavior into five groups. The first two groups - the "touching base" and the "search/deliberation" labels - cover those who visit a few webpages without making a purchase. The latter however has more frequent visits than the former in order to search for additional information and perhaps make subsequent purchases. The third group comprises those who visit several pages and ultimately buy a product. Their visits are therefore primarily (1) to confirm their choices concerning which they had previously gathered information, and later (2) to make an actual purchase. The label for the third group is that of "goal-direct." The final group has the "cart-only" label which includes those who return to their carts filled in previous visit sessions in order to complete their transactions. Using the data extracted from ComScore, Lin, et al. (2010) confirmed that the 
longer the visitors stay on the websites, the higher the value of items in the shopping baskets. Mallapragada, et al. (2016) also used the data from ComScore and performed multi-level analysis to verify that pageview and visit duration are positively related to purchase decision. Yet, only pageview was related to basket value. Similarly, Olbrich and Holsing (2011) used the clickstream panel data to validate that the electronic commerce purchase is a result of the amount of time spent at the websites. The difference between pageviews and that of visit duration was significant between search and experience items (Tangmanee, 2017). From the business standpoint, the positive correlation among pageview, and length of stay could be expected in the electronic commerce context. Mallapragada, et al. (2016) confirmed the positive connections using clickstream panel data. Similar findings were also reported in Olbrich and Holsing (2011). While empirical research on online behavior on retail websites is established, behavior on pornography websites is scant. Given the non-transactional nature of an adult website, its owner may expect a high frequency of long visits (Keilty, 2018). Hence, advanced technology together with analytic techniques have been recommended to draw and retain visitors to the websites. Using a qualitative style, Brenan (2018) described how homosexual website owners set up a network system that connects multiple gay websites in order to retain visitors within the network. There are also reports in trade magazines and newspapers presenting a broad picture of visit behaviors such as the number of unique visitors to mainstream adult websites or which age group most enjoyed online pornography (Hendy, 2017; Pornhub Insights, 2017; Silver, 2018). For instance, in $2012,32 \%$ of participating teenagers stated that they purposely visited online pornography (McAfee, 2018). In the same year, a survey of Internet users in the UK confirmed that the British regularly visited adult websites evenly across age groups. Those between 16-24 years of age appeared to constitute the relatively largest group (Prescott, 2018). Yet, none has reported the number of pages visited or examined the link between pageview and visit duration in the adult website context.

Typically, profits in online adult business may not be from a purchase but from the high traffic (Lai, et al., 2017; McCormack \& Wignall, 2017). Consequently, we doubt if the correlation between the pageview and the visit duration still holds positive in the pornography website context. Our attempt to locate previous work on viewing online pornography led to only qualitative work by Dawning Jr., Schrimshaw, Antebi \& Siegel (2014). Their finding relevant to our research purpose is that the content on potentially high-risk sexual behavior appears to relate to the high number of pageviews. While pornography website visitors enjoy the online adult content, their length of stay on the particular page could be reasonably long but the number of pages they visit might be small. This may consequently undermine the findings in which the pageviews and the duration are positively correlated. It therefore challenges us to examine such correlation specifically in the context of pornography websites. The general hypothesis statement is therefore to test whether the correlation between the two variables is still statistically significant.

\section{Research and Methodology}

\section{Data Preparation}

To respond to the study's objectives, we obtained session-level household panel data from the ComScore online behavior panel for 2016. The data include the visit behavior to the large number of websites in the United States. It consists of an enormous volume of online activities ComScore has explicit permission to gather and record. With the subscription fee, we are allowed to extract the data relevant to our study's purposes. We selected the data from January 1 until May 31, 2016, resulting in the massive set of data roughly totalling 55.6 million visit sessions. Each session primarily has the visited websites, the session duration (in minutes), and the pageview. Sessions with a duration of less than one minute or a pageview of one or less were subsequently removed because such a short visit may signify an accidental encounter.

The pornography content could be broadly divided into two groups. One group satisfies the general audience and the other targets specific viewers. Note that the latter may be a subset of the former. We further collected the sessions from three sources. First, we extracted from ComScore the sessions from the top five pornography websites listed in various charts offering the most popular adult content (Dawning Jr., et al., 2014). Xvideos is one example. Because of the controversy surrounding pornography issues, we decided to withhold the actual name of the selected five websites. Second, we extracted the sessions from the websites whose extensions are xxx. One possible example could be prom-date.xxx. These two extractions gathered 
the visit sessions at general pornography websites. Finally, we extracted the sessions from the websites, with their names containing the words "gay" or "lesbian". Examples include hotgay, gayasian or sexylesbian. This is aimed at a specific group of viewers, who are basically homosexual. Given the possible duplication across the three sets of the extracted visit sessions to adult websites, we had checked and removed the sessions from a few websites with the xxx extension and their names containing the gay (or the lesbian) word from the $x x x$ set and retaining them in the set that specifically targets homosexual viewers. Note that none of the five most popular pornography websites has the xxx extension. Moreover, we make no claim by which the data extracted is representative of visit sessions to pornography websites. Nonetheless, we have covered the substantial portion of pornography websites, thereby enhancing the validity of our findings.

Through all attempts of data extraction, we were able to extract a total of 433,568 visit sessions to pornography websites for a general audience and 40,272 sessions to the websites for specific (i.e., homosexual) viewers. 417,568 of the 433,568 sessions were from the top five pornography websites and the rest $(16,029)$ were from those with the xxx extension. Regarding the pornography websites for homosexual viewers, 33,950 of the 40,272 extracted sessions were from the websites, of which the names contain the word 'gay' and the rest $(6,322)$ were from those with the word 'lesbian' as part of their domain names. As a result, our data set for further analyses has a total of 473,840 visit sessions.

Since our primary aim was to test whether the correlation between the pageview and the visit duration frequently found to be positive in the online retail context still holds in the pornography context, we chose to extract similar data from Amazon.com and YouTube.com and use them as a benchmark for comparison to our findings. The correlations between these two variables were previously found to be positive on the online retail websites (Lin, et al., 2010). We thus selected Amazon in order to validate the correlation discovered in the pornography context against those on this website. The total number of the extracted visit sessions to Amazon in our study was 277,334 . We also included the visit data at YouTube because it shares the similarity with our selected pornography websites in that all are the content-sharing websites. The total number of the extracted visit sessions to YouTube is $2,387,911$. So, if the correlations between pageview and visit duration in our selected pornography websites are in line with those in YouTube, it would offer support to our findings and strengthen their quality.

\section{Data Analysis}

In addition to the descriptive statistics explaining the pageview and the visit duration, we adopted correlational analysis to test the relationship between the two constructs. Finally, we used Fisher's $r$ transformation to test if the correlation coefficients between the two groups of websites were statistically significant. SPSS was used for the report of descriptive statistics and that of the correlational analysis, $\mathrm{R}$ language was used for the Fisher's $r$ transformation test.

\section{Result and Discussion}

Table 1 presents the descriptive statistics of the study's two main constructs (i.e., pageview and visit duration). The detail was classified based on whether the data were from the pornography websites for general or those for specific (i.e., homosexual) viewers. In total, viewers spent on average 11.60 minutes per visit to pornography websites and viewed approximately 12.56 pages. Also, Table 1 shows the average pageviews and visit durations of sessions for the pornography websites for general and for homosexual viewers. It appears that visitors to general pornography websites spent on average roughly twice as long than those visitors to the homosexual ones. The average number of pages they viewed in general online pornography were also approximately twice as high as those in specific ones. 
Chatpong Tangmanee / International Journal of Research in Business and Social Science, Vol 8 No 3, Special Issue 2019 ISSN: 2147-4486

Table 1: Descriptive statistics of pageview and visit duration classified by targeted viewers of pornography websites

\begin{tabular}{|l|l|c|c|c|}
\hline Viewers of pornography websites & Mean & $\begin{array}{l}\text { Standard } \\
\text { deviation }\end{array}$ & Skewness & Kurtosis \\
\hline Homosexual target (visit sessions=40,272) & & & & \\
\hline Pageview & 6.41 & 25.41 & 13.54 & 242.20 \\
\hline Visit duration (minutes) & 7.11 & 22.95 & 12.15 & 211.68 \\
\hline General target (visit sessions=433,568) & & & & \\
\hline Pageview & 13.12 & 51.09 & 203.09 & $66,089.14$ \\
\hline Visit duration (minutes) & 12.02 & 19.69 & 6.22 & 107.29 \\
\hline Total (visit sessions=473,840) & & & & \\
\hline Pageview & 12.56 & 49.47 & 204.94 & $68,832.15$ \\
\hline Visit duration (minutes) & 11.60 & 20.03 & 6.93 & 121.67 \\
\hline
\end{tabular}

Table 2 presents the descriptive statistics of the pageview and the visit durations at the pornography websites for general viewers as classified by whether they are the five most popular pornography websites or they have the xxx extension. It appears from the figures in Table 2 that viewers spent much longer time on the top five websites (i.e., 12.22 minutes) than on the websites with the $x x x$ extension (i.e., 6.62 minutes). Regarding the pageview, the figures in Table 2 confirm the pattern similar to that for visit duration. Similar in detail to Table 2, the sessions to adult websites for homosexual viewers are given in Table 3 . It appears that gay viewers had longer visit sessions and viewed more pages than the lesbian audience. An observation of their skewness and kurtosis statistics together with visual inspection clearly confirm the data in Tables 1, 2, and 3 not being normally distributed. As a result, we transformed the pageview using the logarithm function and the visit duration using the power function, after which their distributions appear normal and ready for parametric correlational analysis using Pearson's correlation coefficients.

Table 2: Descriptive statistics of pageview and visit duration classified by the two groups of pornography websites satisfying general viewers

\begin{tabular}{|c|c|c|c|c|}
\hline Types of pornography websites targeting general audience & Mean & $\begin{array}{c}\text { Standard } \\
\text { deviation }\end{array}$ & Skewness & Kurtosis \\
\hline Websites with the xxx extension (visit sessions=16,029) & & & & \\
\hline Pageview & 8.06 & 22.64 & 13.54 & 242.19 \\
\hline Visit duration (minutes) & 6.62 & 12.35 & 5.55 & 63.26 \\
\hline Top five popular websites (visit sessions=417,539) & & & & \\
\hline Pageview & 13.33 & 51.87 & 201.57 & $64,626.10$ \\
\hline Visit duration (minutes) & 12.22 & 19.89 & 6.19 & 106.43 \\
\hline Total (visit sessions=433,568) & & & & \\
\hline Pageview & 13.12 & 51.09 & 203.09 & $66,089.14$ \\
\hline Visit duration (minutes) & 12.02 & 19.69 & 6.22 & 107.29 \\
\hline
\end{tabular}

Pearson's correlation coefficients between pageview and visit duration are reported in Table 4. The findings exhibit four highlights. First, the correlation between the two variables in the online pornography context is significantly positive, and its magnitude is 0.771 . Second, the visit sessions at the pornography websites with the $\mathrm{xxx}$ extension seem to have relatively low relationship compared to those in the five most popular websites. Third, the relationship in the pornography websites targeting homosexual viewers appears to be higher than that in the websites for general audience. Finally, the correlation between these two constructs (0.789) among gay viewers of adult websites seems to be stronger than that (0.688) among lesbian viewers. The outcome of Fisher's $r$ transformation test yielded a $Z$ value of 16.37 and a $p$-value of .000 , confirming the significant difference of the correlation coefficients between the two groups. According to the result of Fisher's $r$ transformation test $(z=6.6$ and $p$-value $=.000)$, the difference between the two correlation coefficients in the pornography website with the xxx extension (i.e., .727) and in those top five (i.e., .764) is statistically significant. Discussion of these four highlights follows in the next section. 
Chatpong Tangmanee / International Journal of Research in Business and Social Science,

Vol 8 No 3, Special Issue 2019 ISSN: 2147-4486

Table 3: Descriptive statistics of pageview and visit duration classified by two types of pornograph websites satisfying homosexual viewers

\begin{tabular}{|c|c|c|c|c|}
\hline $\begin{array}{c}\text { Types of pornography websites targeting homosexual } \\
\text { audience }\end{array}$ & Mean & $\begin{array}{c}\text { Standard } \\
\text { deviation }\end{array}$ & Skewness & Kurtosis \\
\hline Websites targeting gay viewers (visit sessions=33,950) & & & & \\
\hline Pageview & 6.95 & 27.49 & 12.60 & 208.32 \\
\hline Visit duration (minutes) & 7.53 & 24.38 & 11.78 & 195.02 \\
\hline Websites targeting lesbian viewers (visit sessions=6,322) & & & & \\
\hline Pageview & 3.51 & 6.89 & 14.37 & 412.95 \\
\hline Visit duration (minutes) & 4.87 & 12.57 & 8.02 & 94.74 \\
\hline Total (visit sessions=40,272) & & & & \\
\hline Pageview & 6.41 & 25.41 & 13.54 & 242.20 \\
\hline Visit duration (minutes) & 7.11 & 22.95 & 12.15 & 211.68 \\
\hline
\end{tabular}

Table 4: Correlation coefficients between pageview and visit duration

\begin{tabular}{|c|c|}
\hline Types of pornography websites & Correlation coefficients \\
\hline Overall & $0.771^{* * *}$ \\
\hline Websites targeting general viewers & $0.762^{* * *}$ \\
\hline Websites with the xxx extension & $0.727^{* * *}$ \\
\hline Top five popular porn websites & $0.764^{* * *}$ \\
\hline Websites targeting homosexual viewers & $0.778^{* *}$ \\
\hline Websites targeting gay viewers & $0.789^{* * *}$ \\
\hline Websites targeting lesbian viewers & $0.688^{* * *}$ \\
\hline
\end{tabular}

To validate the 0.771 correlation coefficient between pageview and visit duration in the pornography websites, we extracted similar data from the YouTube and Amazon websites and calculated the coefficients between the two variables in the Amazon and YouTube websites. Table 5 presents the descriptive statistics and the correlation coefficients which are 0.820 for the Amazon and 0.863 for the YouTube websites. Both are statistically significant. It is subsequently reasonable to state that the relationship between pageview and visit duration appears strongest for YouTube, followed by that for Amazon, and that for the pornography websites is relatively the smallest.

People share sexually explicit content on adult websites. A comparison of the pageview and the visit duration between these two groups (see Table 5 for details) shows that YouTube visitors viewed a lower number of webpages (8.49) than pornography website visitors (12.56) but they stay at YouTube (24.37 minutes) longer than at the adult websites (11.60 minutes). Also, Table 5 illustrates the visit length per page at the three websites. Visitors to YouTube spent 2.87 minutes per page. It is the longest stay per page, followed by 1.05 minutes per page at Amazon. The shortest length of stay per page was at the pornography websites - at 0.92 minutes per page.

Table 5: Pageview, visit duration and its correlation coefficients: Amazon.com and YouTube.com

\begin{tabular}{|l|c|c|c|c|c|c|}
\hline \multicolumn{1}{|c|}{ Websites } & \multicolumn{2}{|c|}{ Pageview } & \multicolumn{2}{c|}{ Visit duration (minutes) } & $\begin{array}{c}\text { Visit Duration per page } \\
\text { (minutes/page) }\end{array}$ & $\begin{array}{c}\text { Correlation } \\
\text { coefficients }\end{array}$ \\
\hline & Mean & $\begin{array}{c}\text { Standard } \\
\text { deviation }\end{array}$ & Mean & $\begin{array}{c}\text { Standard } \\
\text { deviation }\end{array}$ & & \\
\hline YouTube & 8.49 & 15.65 & 24.37 & 38.06 & 2.87 & $0.863^{* * *}$ \\
\hline Amazon & 9.33 & 16.81 & 9.83 & 17.77 & 1.05 & $0.820^{* * *}$ \\
\hline Pornography & 12.56 & 49.47 & 11.60 & 20.03 & 0.92 & $0.771^{* * *}$ \\
\hline
\end{tabular}

${ }^{* * *}$ significant at 0.05 . 


\section{Conclusions}

Previous research has confirmed the positive connection between pageview (the number of pages visited) and visit duration at electronic commerce websites (Mallapragada, et al., 2016; Tangmanee, 2017). That is, the higher the pageviews, the longer the duration, and vice versa. Yet, we doubted whether the positivity still holds in the context of pornography websites. A subscription to ComScore allows us to extract data in order to examine such correlations. Given the data from the pornography websites for the general audience and from those aiming to satisfy the homosexual audience, the visitors to pornography websites had an average of 11.60 minutes per stay during which they viewed approximately 12.56 webpages. Because no previous work had reported pageview and visit duration in pornography websites, we had to discuss our findings with those within the online retail context. Using data from ComScore, Tangmanee (2017) confirmed that visitors to the top three retail websites spent on average 29.5 minutes and visited 35.3 webpages. Mallapragada, et al., (2016) reported the average pageviews of 201.1 pages and an average stay of 20.2 minutes. Compared to the results on online retail, our findings confirmed that visitors to pornography websites tend to spend shorter time on the websites and to view a lower number of pages than those visitors to online retail websites.

Given the significant correlation coefficient of 0.771 , the pageview and the visit duration on pornography websites are positively related. We must therefore admit that our initial conjecture in which the correlation in pornography websites should not hold positive is inaccurate. It is however significantly positive and in line with the findings for the online retail context (Lin, et al., 2010; Mallapragada, et al., 2016; Tangmanee, 2017). In other words, the more pages the visitors view, the longer they stay on the pornography websites, and vice versa. In a similar context, the significant correlation for Victoriassecret.com was 0.771 (Tangmanee, 2017). Similar findings were also reported by Mallapragada, et al. (2016). Moreover, such a significant and positive correlation between these two variables is evident both for the adult websites for general viewers for its coefficient of 0.762 and for those for the homosexual audience for its coefficient of 0.778 .

Regarding the viewer's sexual orientation, the pornography websites were broadly classified into two groups in which online behaviors were extracted in the current study. One group practically targeted everyone above legal age and the other specifically aimed homosexual viewers. As such, we selected data from ComScore in order to fit the two categories of pornography websites. The first category was from the two groups of adult websites. One group consisted of the top five pornography websites as listed on several charts and reports, and the other group contains those with the xxx extension. Hence, this first category targets general viewers. Directly aimed at homosexual viewers, the second category comprised websites in which the "gay" or "lesbian" word was part of their domain names - the former for male and the latter for female homosexuals. Based on our findings, all correlation coefficients in the four groups (see Table 4 for detail) were positively significant.

Comparing the 0.762 correlation coefficient between pageview and visit duration for the adult websites targeting the general viewers with that of 0.778 for those for the homosexual audience, it appears that the contents in the homosexual websites are more to the taste of their target than those in the online collection for general viewers. Our speculative remark is made from the higher coefficient in the homosexual category than that in the general one. It may further signify a moderating effect of the viewers' sexual orientation on their visit behavior on pornography websites.

Considering only the adult websites for conventional viewers, the coefficient of 0.764 for the top five leading pornography websites is significantly higher than that of 0.727 for the websites with the xxx extension. This therefore confirms that the viewers of the top five leading adult websites are of greater interest to the pornographic contents than those of the websites with the xxx extension. In other words, the content of the former is more arousing than the latter.

Alternatively, a look at the pornography websites targeting homosexuals presents interesting findings. How the gay audience enjoys the adult content appears to be more intense than the lesbian viewers since the former's correlation between pageview and visit duration is significantly higher than the latter's. While the gay website viewers in the current study watched about 7 pages within 7.5 minutes in one visit, the lesbian 
ones viewed roughly half within 5 minutes. Such different viewing behavior may challenge researchers to explore not only the moderating effect of the viewers' sexual orientation, but also the similar effect of whether the homosexual is male or female on how they watch online pornography (McNeil, Osbone, \& Pavia, 2005). Given no previous empirical work specifically addressing the issue, we are unable to offer further suggestions.

To validate the correlation in the online pornography context, we did have similar coefficients from two websites for comparison. One is YouTube.com, the top leading content-sharing website and the other is Amazon.com, the widely accepted online retail website. Their correlation coefficients between pageviews and visit duration are 0.863 , and 0.820 , respectively. Both are statistically significant. Consequently, we are able to state that visit behavior (i.e., the number of pages visited and the length of stay at the website) on pornography websites is more similar to that on retail websites (e.g. Amazon) than that on content-sharing websites (e.g., YouTube). This may reflect the business orientation of online pornography, despite its nontransactional website. Although offering no items for purchase, adult websites have been known to earn profit through the high volume of traffic at their websites (Desjardins, 2017) to which our finding lends empirical support. The visit duration of 0.92 minutes per page confirms the shortest length of stay at pornography websites as compared to the 2.87 minutes at YouTube or the 1.05 at Amazon (see Table 5 for details). Such a brief stay may signify the instant hop between webpages, enhancing the amount of online traffic. This ultimately results in the high business success of pornography websites. According to Brennen (2018), an advanced computer algorithm was adopted so one visit at an online adult collection would lead to a sizeable financial yield. Browsing behavior on a pornography website may also trigger additional visits to other sites such as adult toy websites. This undoubtedly creates massive traffic volume (Keilty, 2018; Kimball, 2017). Nonetheless, this is only our conjecture regarding the comparison of visit behavior among content-sharing websites, an online pornography collection and web-based retail stores. It should challenge fellow researchers to examine this unexplored context.

Our findings offer both theoretical and practical contributions. Theoretically, we have reported online behavior and tested the correlation between pageview and visit duration on pornography websites. According to our findings, the significant positive relationship is still substantiated. This is consistent with the correlation found in YouTube or Amazon. Our unique theoretical contribution came from the exploration into the online behavior on websites targeting homosexual viewers. To a certain degree, sexual orientation is found in the current study to have an impact on online behavior on pornography websites. Moreover, our findings empirically support the business feasibility of online pornography, despite the industry's negative appearance to the public.

Practically, we have two major recommendations for electronic commerce practitioners. First, online business web administrators may increase the amount of traffic on pornography websites through the manipulation of pageview and visit duration. That is, adding the sexually explicit content to the website may yield higher pageviews as well as longer stays at the website. This could consequently lead to heavy traffic. Such busy online traffic could result in high financial return. Second, practitioners in the online business aiming at the homosexual target must be aware of unique visit behavior on pornography websites. Since the adult websites for general viewers may offer services for both heterosexual and homosexual audiences, we are unable to point to any specific difference between pornography websites for the public and those for homosexual viewers. Nonetheless, our exploration may suggest that online practitioners should be attentive to the services targeting female homosexuals for the smallest correlation between pageview and visit duration as compared to the other groups of viewers.

Similar to other research efforts, the current study has limitations. The online events are extremely dynamic. What is valid today may not be the next day. So, continuous effort to examine such fast evolving phenomenon is essential. 


\section{References}

Brennan, J. (2018). Gay porn networks. International Journal of Cultural Studies, 22(1), 1-17. https://doi.org/10.1177/1367877918754536.

Castleman, Michael. (2016). Dueling Statistics: How Much of the Internet Is Porn?. Retrieved on December 8, 2018 via https://www.psychologytoday.com/gb/blog/all-about-sex/201611/dueling-statistics-howmuch-the-internet-is-porn.

Chaffey, D. (2017). Forecast growth in percentage of online retail: Ecommerce sales. Retrieved on January 03, 2017 via https://www.smartinsights.com/digital-marketing-strategy/online-retail-salesgrowth/2017

CovenantEyes. (2015). Pornography statistics: 250+ Facts and Stats About Pornography. Retrieved on January 3, 2017 via http://www.covenanteyes.com/pornography-facts-and-statistics/2015

Danaher, P. J., Mullarkey, G. W., \& Essegaier, S. (2006). Factors affecting web site visit duration: A crossdomain analysis. Journal of Marketing Research, 43(2): 182-194. https://doi.org/10.1509/jmkr.43.2.182.

Davin, J.E. (2017). We control it on our end, and now it's up to you--Exploitation, Empowerment, and Ethical Portrayals of the Pornography Industry. Retrieved on April 18, 2018 via http://cupola.gettysburg.edu/cgi/viewcontent.cgi?article=1620\&context=student_scholarship

D'Ottavio, Domenica. (2018). Social Media's Role in Viral Content Marketing. Retrieved on December 10, 2018 via https://www.frac.tl/social-media-viral-marketing/

Desjardins, Jeff. (2017). The 100 Websites That Rule the Internet. Retrieved on December 10, 2018 via https://www.visualcapitalist.com/100-websites-rule-internet/

Dhyana, B. K. (2018). Anonymity in Browsing and Its Adverse Effects in Cyberspace. Supremo Amicus, 104.

Downing, M. J., Schrimshaw, E. W., Antebi, N., \& Siegel, K. (2014). Sexually explicit media on the Internet: A content analysis of sexual behaviors, risk, and media characteristics in gay male adult videos. Archives of Sexual Behavior, 43(4), 811-821. DOI 10.1007/s10508-013-0121-1.

Hendy. (2017). The top 10 visited porn sites \& how much money they make. Retrieved on January 3, 2017 via http://thechive.com/2017/07/22/the-top-10-visited-porn-sites-how-much-money-they-make-10photos/ 2017

Johnson, J. A. (2011). Mapping the feminist political economy of the online commercial pornography industry: A network approach. International Journal of Media \& Cultural Politics, 7(2), 189-208. DOI 10.1386/macp.7.2.189_1

Keilty, P. (2018). Desire by design: pornography as technology industry. Porn Studies, 5(3): 338-342. https://doi.org/10.1080/23268743.2018.1483208

Kimball, Thomas G. (2017). Why is Pornography So Powerfully Addictive?. Retrieved on December 8, 2018 via https://thedoctorweighsin.com/why-is-pornography-so-powerfully-addictive/

Lai, K., Lee, Y.X., Chen, H. and Yu, R., (2017). Research on Web Search Behavior: How Online Query Data Inform Social Psychology. Cyberpsychology, Behavior, and Social Networking, 20(10): 596-602. DOI: 10.1089/cyber.2017.0261.

Lin, L., Hu, P.J.H., Sheng, O.R.L. and Lee, J. (2010). Is stickiness profitable for electronic retailers?. Communications of the ACM, 53(3): 132-136. DOI: 10.1145/1666420.1666454.

Olbrich, R. and Holsing, C. (2011). Modeling consumer purchasing behavior in social shopping communities with clickstream data. International Journal of Electronic Commerce, 16(2):15-40. https://doi.org/10.2753/JEC1086-4415160202.

Macmillen, Hayley. (2017). 6 Ways Porn Is Different Now Than in the '90s. Retrieved on December 8, 2018 via https://www.cosmopolitan.com/sex-love/a8616324/porn-industry-adult-entertainment-changes

Marshall, C. (2015). By 2019, 80\% of the World's Internet Traffic Will Be Video. Tubular Insights. Retrieved on January 3, 2017 via http://tubularinsights.com/ 2019-internet-video-traffic/2015. 
Mallapragada, G., Chandukala, S.R. and Liu, Q. (2016). Exploring the effects of "What"(product) and "Where"(website) characteristics on online shopping behavior. Journal of Marketing, 80(2): 21-38. http://doi.org/10.1509/jm.15.0138.

McAfee. (2018). Internet activity monitoring best practices. Retrieved on December 10, 2018 via https://tinyurl.com/y8nygryf

McCormack, M. and Wignall, L., (2017). Enjoyment, exploration and education: Understanding the consumption of pornography among young men with non-exclusive sexual orientations. Sociology, 51(5): 975-991. https://doi.org/10.1177/0038038516629909.

McNeil, Legs, Jennifer Osborne, and Peter Pavia. (2005). The other Hollywood: the uncensored oral history of the porn film industry. Walter de Gruyter.

Mercer, John. (2017). Introduction: Gay porn now!. Porn studies. 4(2): 127-130. https://doi.org/10.1080/23268743.2017.1308127.

Moe, W.W., (2003). Buying, searching, or browsing: Differentiating between online shoppers using in-store navigational clickstream. Journal of consumer psychology, 13(1-2): 29-39. https://doi.org/10.1207/S15327663JCP13-1\&2_03

Mosley, Patina (2018). Women \& Pornography. Retrieved on December 8, 2018 via https://downloads.frc.org/EF/EF18F20. pdf

Pallant, J. I., Danaher, P. J., Sands, S. J. and Danaher, T. S. (2017). An empirical analysis of factors that influence retail website visit types. Journal of Retailing and Consumer Services, 39: 62-70. https://doi.org/10.1016/j.jretconser.2017.07.003.

Pornhub Insights. (2017). Celebrating 10 Years of Porn and Data! Retrieved on December 9, 2018 via https://www.dailymail.co.uk/femail/article-4545854/10-year-pornography-survey-reveals-surprisingstatistics.html

Prescott, C. (2018). Internet users, UK: 2018. Retrieved on December 10, 2018 via https://www.ons.gov.uk/businessindustryandtrade/itandinternetindustry/bulletins/ internetusers/2018

Price, R. (2018). Facebook and Instagram will now tell you how much time you spend on them - here's how to find out how addicted you are. Retrieved on December 10, 2018 via https://www. businessinsider.com/facebook-instagram-time-well-spent-2018-7.

Role, M. R. (2017). Trans women in pornography: An exploration of the motivations and experiences of transgender women in the adult film industry. Unpublished doctoral dissertation, The Wright Institute.

Ropelato, Jerry. (2017). Pornography statistics 2017. Top Ten Reviews. Retrieved on April 3, 2019 via https://archive.org/details/perma_cc_L8ZF-D2M8

Royalle, C. (1993). Porn in the USA. Social Text, 37: 23-32. DOI: $10.2307 / 466257$

Silver, C. (2018). Pornhub 2017 Year In Review Insights Report Reveals Statistical Proof We Love Porn. Retrieved on April 3, 2019 via https://www.forbes.com/sites/curtissilver/2018/ 01/09/pornhub-2017year-in-review-insights-report-reveals-statistical-proof-we-love-porn/\#606647b624f5

Statista. (2017). Data volume of global online gaming traffic from 2016 to 2021. Retrieved on January 3, 2017 via https://www.statista.com/statistics/267190/traffic-forecast-for-internet-gaming 2017.

Statista. (2018). eCommerce Report 2018. Retrieved on December, 9, 2018 via https://www.statista.com/study/42335/ ecommerce-report/

Strange But True. (2017). How Big is the Porn Industry?. Retrieved on December, 9, 2018 via https://medium.com/@Strange_bt_True/how-big-is-the-porn-industry-fbc1ac78091b

Tangmanee, C. (2017). Comparisons of Website Visit Behavior between Purchase Outcomes and Product Categories. International Journal of Research in Business and Social Science, 6, 4:1-10. http://dx.doi.org/10.20525/ijrbs.v6i4.760

Xun, J. (2015). Return on web site visit duration: Applying web analytics data. Journal of Direct, Data and Digital Marketing Practice, 17(1): 54-70. https://doi.org/10.1057/dddmp.2015.33 